\title{
Psychological Loneliness and Aggression among psychiatric patients
}

\author{
Zaki , S., M ; Abd El- Kader , N., M ; Fahmy , H., D; Abd El-Aziz , A., M \& Abo EL-Magd , M., H. \\ Psychiatric \& Mental Health Nursing, Faculty of Nursing - El Minia university. \\ Psychiatric -Mental Health Nursing, Faculty Nursing, Cairo University. \\ Community Health Nursing, Assiut University, 4 Psychiatric Nursing, Faculty of Nursing, Assiut University. \\ Psychiatric -Mental Health Nursing, Faculty of Nursing, El-Minia University..
}

\begin{abstract}
:
Aggression and violent behavior are the chief concerns among staff, families and clients at inpatient psychiatric units. The aim of this study was to assess psychological loneliness, and aggression among psychiatric patients. Descriptive correlational research design was used in this study. The sample consisted of 100 psychiatric inpatients at Beni-Ahmad psychiatric hospital in El-Minia governorate. Three tools were utilized to measure the concepts of the study variables: Personal and clinical data Questionnaire, Psychological loneliness scale, and Aggression questionnaire. Results of the study revealed that $42 \%, 35 \%$ and $14 \%$ of patients were diagnosed schizophrenic, depression and manic disorders. Most of them (73\%) had severe psychological loneliness and $51 \%$ had severe level of aggression. In conclusion, more than half of psychiatric patients had severe psychological loneliness and severe level of aggression. Psychological loneliness was negatively correlated with aggression, Recommendations: This study recommended to design and implement a psycho-educational program to decrease psychological loneliness and aggression among the psychiatric patients.
\end{abstract}

\section{Key Words: Psychological loneliness /Aggression/psychiatric patients.}

\section{Introduction:}

It is believed that, individuals with severe mental illnesses are at risk for aggressive behavior, by definition, congregate a number of mentally ill individuals together in a situation that is often crowded, constricted and potentially abrasive. It appears that little practical progress has been made in identifying inpatients that may be at particular risk for aggressive or violent behavior. Although situational variables, such as lax and uncontrolled ward environment can increase the risk of aggression, so there are certain individuals at greater risk for aggressive behavior than others (Steinert et al., 2002).

Quartz \& Sejnowski (2002) classified aggression into main types are: Hostile Aggression: When an act of aggression comes from feelings of anger and is intended to inflict pain. An example of this would be someone stabbing a knife into another person's leg. Obviously, this is an act that is made with the intention of causing pain. It is sometimes called affective, impulsive, or reactive aggression. Instrumental Aggression: Any other act of aggression that isn't intended to cause pain is called instrumental aggression. This might be an older brother wrestling with his younger sibling. The aggression is in good fun and not necessarily to inflict serious pain. Verbal Aggression: is a predisposition to attack the self-concept of others, associated with name-calling, the use of threats, and negativity, resentment, and suspicion. Consequences of verbal aggression include: lower self-concept, frustration, anxiety, anger, embarrassment and physical aggression.

Psychologists have identified a variety of situational factors that produce aggressive behavior, such as provocation, exposure to weapons, a hot environment, unpleasant odors, loud noises, violent media, and physical pain. Examples of personal factors known to increase aggression are hostile attribution bias, narcissism, being male, and a host of beliefs, attitudes, values, and behavioral scripts. Situational and personal factors are not mutually exclusive. Some situational factors give rise to states that closely resemble personal variables; for example, social rejection or playing violent video games can strengthen hostile cognitive biases (Gitter \& Baumeister 2009).

psychological loneliness experienced as the subjective response to the absence of a close and intimate attachment figure, e.g. the lack of a loved one or a spouse. Louks (2004) found that, lonely people scored high level of aggression and low in assertiveness, so it is possible that they have feelings of anger which typically go unexpressed. Loneliness has also been significantly correlated with depression, hopelessness, and aggression. There are many biological and psychological factors such as parental mental disorder and family history 
of depression, being a female adolescent, high trait anxiety and preexisting anxiety disorders, substance abuse and conduct disorder, temperament, reacting negatively to stressors and personality trait of neuroticism, negative thought patterns (pessimism, learned helplessness) and avoidant coping style (Flood,2005).

\section{Significance of the Study:}

To date, few studies have examined the potential relation between psychological loneliness and aggression in psychiatric patient populations. So it is helpful for nursing profession to explore several potential risk factors related to psychological loneliness, and aggression that may place certain psychiatric patients at higher risk for aggressive behavior to manage them properly.

\section{Patients and Methods}

Research design: Descriptive correlational research design was used in this study.

Setting of the study: This study was conducted in Beni-Ahmad psychiatric hospital at El-Minia governorate, this hospital is affiliated to ministry of health.

Subjects \& sample: A convenient sample of 100 psychiatric patients was recruited in the study according to the following inclusion criteria: Recently admitted patients (duration of hospitalization not more than two weeks). Their age ranged from 20-45 years and duration of illness not less than one year. Data collection started from May to October 2011.

Tools of data collection:

\section{1- Personal and clinical data questionnaires:}

An interview questionnaire sheet was developed by the researcher and covered the following items: Personal data, date of admission, duration of illness and diagnosis.

\section{2- Psychological loneliness scale}

Loneliness scale was developed by Russell (1996) to assess subjective feelings of loneliness. It consists of 20 statements. Subjects were asked to answer on 4-point likert scale format ranging from 1 to 4 for positive statements. The degree of loneliness was categorized according to the following scores: 20-39 is considered mild loneliness, 40-59 is moderate and 60-80 is considered severe loneliness. This scale was translated into Arabic version by El-Dosoky, (1996). Reliability of this scale was done by the researcher is 0.97 (Alfa- coefficient).

3-Aggression questionnaire Buss and Perry (1992):

This questionnaire was developed by Buss and Perry (1992). It is a self-reported measure that consisted of 29 items through four subscales; namely (9) items for "Physical aggression", (5) items. for "verbal aggression", (7) items for "anger" and ( 8 items). For "hostility". Subjects were asked to answer on a 3-point likert scale format which ranged from 1 (Extremely uncharacteristic of me), 2 (somewhat characteristic of me) to 3 (Extremely characteristic of me). Total score of 29-44 is considered mild aggression, 45-74 is moderate and 75-87 is considered severe level of aggression. Validity of this scale was estimated. The investigator used and followed the "Back translation procedure" for verifying the translation of aggression scale.

\section{Ethical Consideration}

The purpose of this study was explained for every interviewed psychiatric patient (males \& females).The patient has the ethical right to agree or refuse participation in the study, informed consent to participate in the study was obtained from educated patients and verbal one obtained from uneducated psychiatric patients, they informed that the information obtained will be confidential and used only for the purpose of the study and there was no any risk for their participation.

\section{Procedure}

A review of related literature covering various aspects of the problem was done using available journals and books to be acquainted with the research problem and to select the appropriate study tools. An official permission was granted from the director of Beni-Ahmad psychiatric hospital at ElMinia governorate to conduct the study. The aim of the study was explained by the researcher through direct personal communication with the patients for getting their approval prior starting their participation in the study to gain their cooperation, as well as voluntary participation and confidentiality were assured

\section{Statistical Analysis}

Subjects' responses to each category were analyzed, categorized and coded by investigator then tabulated separately by using the statistical package for social science (SPSS) version 12. Descriptive statistics were calculated as frequency, percentage, mean, stander deviation. T-test and ANOVA test and Pearson correlation were also used among studied values. Probability (p-value) less than 0.05 is considered significant and less than 0.001 is considered highly significant

\section{Pilot Study}

A pilot study was done to evaluate the questionnaires clarity and applicability as well as the time needed to fulfill each sheet. It was carried out on a sample of 15 patients and they were excluded from the actual study sample. 


\section{Results:}

Table (1) Distribution of demographic and clinical characteristics of the studied patients. $(\mathrm{N}=100)$

\begin{tabular}{|l|c|c|}
\hline $\begin{array}{l}\text { Demographic \& clinical } \\
\text { characteristics }\end{array}$ & No & Frequency \\
\hline The age groups & & \\
- 20-35 yrs & 79 & $79 \%$ \\
- 36-45yrs & 21 & $21 \%$ \\
\hline Gender & & \\
- Males & 63 & $63 \%$ \\
- Females & 37 & $37 \%$ \\
\hline Residence & & \\
- Rural areas & 54 & $54 \%$ \\
- Urban areas & 46 & $46 \%$ \\
\hline level of education & & \\
- Illiterate & 16 & $16 \%$ \\
- Read \& write & 36 & $36 \%$ \\
- Secondary & 39 & $39 \%$ \\
- University & 9 & $9 \%$ \\
\hline Marital status & & \\
- Single & 39 & $39 \%$ \\
- Married & 53 & $53 \%$ \\
- Divorced & 4 & $4 \%$ \\
- Widow & 4 & $4 \%$ \\
\hline Occupation & & \\
- Working & 48 & $48 \%$ \\
- Not working & 52 & $52 \%$ \\
\hline Diagnoses & & \\
- Schizophrenia & 42 & $42 \%$ \\
- Depression & 35 & $35 \%$ \\
- Mania & 14 & $14 \%$ \\
- Delusional disorders & 7 & $7 \%$ \\
- Personality disorders & 2 & $2 \%$ \\
\hline
\end{tabular}

Table (2): Total Score of Psychological Loneliness among the Patients $(\mathrm{N}=100)$

\begin{tabular}{|c|c|c|}
\hline Psychological loneliness & N & \% \\
\hline Mild loneliness & 1 & 10 \\
& 0 & $\%$ \\
\hline Moderate loneliness & 1 & 17 \\
& 7 & $\%$ \\
\hline Severe loneliness & 7 & 73 \\
& 3 & $\%$ \\
\hline
\end{tabular}

Table (1) showed that, the age of the studied patients was ranged between 20- 45 years. $79 \%$ of them were in the age group between 20-35 years,
$63 \%$ were males, $54 \%$ from rural areas, $39 \%$ of patients were educated in secondary school. It was also observed that, the highest percentage of the patients $(53 \%)$ were married, $52 \%$ did not work and $42 \%$ had schizophrenic disorders, $35 \%$ were depressed and $14 \%$ were manic.

Table (2) demonstrated the highest percentage of the patients $(73 \%)$ had severe psychological loneliness. In table (3) half of the patients (51\%) had severe level of aggression and $49 \%$ of them had moderate aggression.

As noted from table (4a) There was a significant difference between psychological loneliness and age (p. value $=0.035$ ). The total mean score of psychological loneliness was increased among patients in age group (36yrs-45yrs), Regarding gender, there was no significant difference between gender and psychological loneliness, While there was a significant difference between gender and aggression ( $\mathrm{p}$. value $=0.04$ ). For gender differences, it was proved that, the total mean score of aggression was increased in males.

Regarding marital status, there was no significant difference between marital status and psychological loneliness and aggression, while widowed patients had the highest level of psychological loneliness. The total mean scores of aggression have increased in divorced and married patients $(2.58 \pm 0.51)-(2.75 \pm 0.51)$ respectively (table 5). There were significant differences between diagnoses and psychological loneliness and aggression. The total mean score of psychological loneliness was increased in depressed patients. The total mean score of aggression was increased in patients with manic disorder and delusional disorders $(2.86 \pm 0.36)-(2.71 \pm 0.49)$ respectively (table 6). Psychological loneliness was negatively correlated with aggression, (table 7). 
Table (3): Total score of aggression among the studied patients $(\mathrm{N}=100)$

\begin{tabular}{|c|c|c|}
\hline Aggression & N & \% \\
\hline Mild aggression & 0 & $0 \%$ \\
\hline $\begin{array}{c}\text { Moderate } \\
\text { aggression }\end{array}$ & 49 & $49 \%$ \\
\hline $\begin{array}{c}\text { Severe } \\
\text { aggression }\end{array}$ & 51 & $51 \%$ \\
\hline
\end{tabular}

Table (4): Difference Between Demographic Characteristics andPsychological Loneliness and $\operatorname{Aggression}(\mathbf{N}=100)$

\begin{tabular}{|l|c|c|}
\hline \multicolumn{1}{|c|}{ Items } & $\begin{array}{c}\text { Psychological } \\
\text { Loneliness }\end{array}$ & Aggression \\
\cline { 2 - 3 } & Mean \pm SD & Mean \pm SD \\
\hline Age group: & & \\
20 yrs-35yrs & $2.56 \pm 0.71$ & $2.51 \pm 0.51$ \\
36yrs-45yrs & $2.99 \pm 0.31$ & $2.52 \pm 0.51$ \\
T-test & 4.431 & 0.020 \\
P value & $0.035^{*}$ & 0.887 \\
\hline Gender: & & \\
Male: & $2.57 \pm 0.71$ & $2.59 \pm 0.51$ \\
Female & $2.73 \pm 0.56$ & $2.38 \pm 0.49$ \\
T-test & 1.066 & 4.031 \\
P value & 0.302 & $0.045^{*}$ \\
\hline Residence: & & \\
Urban & $2.57 \pm 0.72$ & $2.54 \pm 0.51$ \\
Rural & $2.69 \pm 0.61$ & $2.48 \pm 0.51$ \\
T-test & 0.640 & 0.378 \\
P value & 0.424 & 0.539 \\
\hline Level of education: & & \\
Illiterate & $2.87 \pm 0.34$ & $2.38 \pm 0.51$ \\
Read \& write & $2.61 \pm 0.73$ & $2.61 \pm 0.49$ \\
Secondary & $2.56 \pm 0.72$ & $2.46 \pm 0.51$ \\
University & $2.56 \pm 0.53$ & $2.56 \pm 0.53$ \\
F-test & 0.906 & 1.017 \\
P value & 0.44 & 0.38 \\
\hline Marital status: & & \\
Single & $2.54 \pm 0.64$ & $2.44 \pm 0.51$ \\
Married & $2.66 \pm 0.71$ & $2.58 \pm 0.51$ \\
Divorced & $2.75 \pm 0.51$ & $2.75 \pm 0.51$ \\
Widow & $3.01 \pm 0.01$ & $2.01 \pm 0.01$ \\
F-test & 0.742 & 2.458 \\
P value & 0.53 & 0.06 \\
\hline Occupation: & $2.58 \pm 0.71$ & $2.58 \pm 0.51$ \\
Work & $2.67 \pm 0.62$ & $2.44 \pm 0.51$ \\
Not work & 0.312 & 1.967 \\
T-test & 0.57 & 0.16 \\
P value & & \\
\hline & & \\
\hline
\end{tabular}

Table (5): Difference Between Diagnoses and Psychological loneliness and Aggression $(\mathrm{N}=100)$

\begin{tabular}{|l|c|c|}
\hline \multirow{2}{*}{ Diagnoses: } & $\begin{array}{c}\text { Psychological } \\
\text { Loneliness }\end{array}$ & Aggression \\
\cline { 2 - 3 } & Mean \pm SD & Mean \pm SD \\
\hline Schizophrenia & $2.74 \pm 0.45$ & $2.71 \pm 0.46$ \\
\hline Depression & $2.97 \pm 0.17$ & $2.09 \pm 0.28$ \\
\hline Mania & $1.43 \pm 0.76$ & $2.86 \pm 0.36$ \\
\hline Delusional & $2.86 \pm 0.38$ & $2.71 \pm 0.49$ \\
\hline $\begin{array}{l}\text { Personality } \\
\text { disorders }\end{array}$ & $2.01 \pm 0.01$ & $2.51 \pm 0.71$ \\
\hline F-test & 35.447 & 15.931 \\
\hline P value & $0.018^{*}$ & $0.010^{*}$ \\
\hline
\end{tabular}

Table (6): Correlation between Psychological loneliness, and Aggression( $\mathrm{N}=100)$

\begin{tabular}{|c|c|c|c|}
\hline \multicolumn{2}{|c|}{ Variables } & $\begin{array}{c}\text { Psychological } \\
\text { loneliness }\end{array}$ & Aggression \\
\hline \multirow{4}{*}{$\begin{array}{c}\text { Psychological } \\
\text { loneliness }\end{array}$} & $\begin{array}{c}\mathbf{P} \\
\text { value }\end{array}$ & --- & --- \\
\cline { 2 - 5 } & $\mathbf{P a l u e}$ & $0.03 *$ & --- \\
\cline { 2 - 5 } & $\begin{array}{c}\mathbf{P} \\
\text { value }\end{array}$ & $0.00^{* *}$ & --- \\
\hline \multirow{3}{*}{ Aggression } & $\mathbf{R}$ & -0.13 & 1 \\
\cline { 2 - 5 } & $\begin{array}{c}\mathbf{P} \\
\text { value }\end{array}$ & 0.21 & --- \\
\hline
\end{tabular}

\section{Discussion:}

The study results revealed that, $(73 \%)$ of the patients were suffering from severe psychological loneliness. This could be explained by two factors, first factor is related to the nature of psychiatric disorders, where nearly half of patients had extreme level of depression and schizophrenia. As in depressed patients they have feeling of anhedonia (loss of interest), depressed mood, low self-esteem, low social competence, poorer quality social interactions, which consider a main cause of feeling of psychological loneliness. Added to this, psychological loneliness is described as one of the most fundamental problem for patients with 
schizophrenia (West et al., 2006). Hospitalization could be another factor for feeling of psychological loneliness in which the patients away from their families, friends, and familiar persons. This finding was consistent with Asher\& Paquette (2003) who found that, $79 \%$ of patients occasionally felt lonely, this feeling of loneliness has also been linked to low social competence, people rejection and victimization, lack of high quality friendships, and more negative appraisals of social support. The total mean score of psychological loneliness was high among patients in age group (36- 45 yrs). This could be explained by that, this period is considered a productive age for work and having income but patients found themselves hospitalized and after discharge, people refuse to deal with them as psychiatric patients especially in manual occupation related to stigma of mental illness. Therefore, they feel socially rejected, having feeling that there is nobody supporting them (Cattan \& White 2005). Supporting to these results Flood (2005) found that, psychological loneliness is increased among patients between the ages of 25 - 44 years and they reported significantly lower levels of support and friendship.

In this study, it was found that the total mean score of psychological loneliness was increased among female patients, This result could be explained by the fact that, women are the core of the family, sensitive and more sociable in their nature, when they become hospitalized, they lose their social network, be away from their friends and neighbors. In this respect, Flood (2005) found that, women were more reported feeling of lonely than men. Also Hawkley et al., (2008) in a comprehensive review of gender difference in adult loneliness research, observed that, females are more likely than males to being lonely.

Needless to say that people are sociable by their nature and desire interaction with others. In this study, it was found that, widowed patients had highest level of psychological loneliness. This result could be related to that, they lose their (husbands or wives), they lose some one who made them feel be loved and appreciated worth of value. This loss considered as a main factor of their psychological loneliness and psychiatric illness. Consistent with the present study results, Dykstra \& Fokkema (2007) and Flood (2005) reported that, loneliness is greater among those who have widowed and divorced. Regarding diagnoses and psychological loneliness, it was observed that, the highest mean score of psychological loneliness was found in depressed patients, this could be explained by that loneliness is a leading factor of depression. This finding is consistent with Heinrich and Gullone (2006) who stated that, loneliness is one of the main factors leading to depression and an important cause of suicide and suicide attempts.

Concerning patient's aggression, the study results proved that, more than half of patients had severe level of aggression and the highest mean score of aggression was found among manic and schizophrenic patients. Similarly, Junginger \& McGuire (2004) found that, patient who is in a manic phase of their illness present an increased risk of aggression. This could be explained by that, the majority of patients were schizophrenic. There is much evidence that schizophrenic patients have an increased risk for aggression and violent behavior, including homicide Milton et al. (2008).

Males with schizophrenia commit severe acts of aggression more frequently than females as stated by Lincoln et. al., (2007). This support the study findings that, the high mean score of aggression was found in males patients. This could be due to the nature of patients illness, the majority of them diagnosed as schizophrenic. Other cause of aggression may be due to hormonal secretions which create a propensity for certain behaviors such as "testosterone seems most strongly linked to competitiveness and aggression among males. These findings were consistent with the results of Monahan et. al., (2001) who stated that, high testosterone levels have been found in men like prisoners and hospitalized psychiatric patients.

The study findings revealed that psychological loneliness was negatively correlated with aggression, Flood (2005) stated that, lonely individuals are more negative in their evaluations of potential acquaintances. Similarly Weiss (2002) claimed that, loneliness produces an oversensitivity to minimal cues and attendance to misinterpret and exaggerate the aggressive intent to others. Indeed, Louks (2004) found that, lonely people scored high level of aggression and low in assertiveness, so it is possible that they have feelings of anger which typically go unexpressed. Loneliness has also been significantly correlated with aggression.

\section{Conclusion:}

Based on the results of the present study, it concluded that, psychiatric patients had severe psychological loneliness and severe level of aggression. The highest mean score of psychological loneliness was increased in female patients than in male patients. The total mean score of aggression was increased among male patients. Psychological loneliness was negatively correlated with aggression.

\section{Recommendations:}

Based on the results of the present study, the following recommendations are suggested: Designing 
and implementing psycho-educational program to decrease psychological loneliness and aggression among the psychiatric patients.

\section{References:}

1- Asher S., \& Paquette J., (2003): Loneliness and peer relations in childhood. Current Directions in Psychological Science: 12, 75-78.

2-Buss A. \& Perry N., (1992):Aggression questionnaires. Journal of Personality and Social Psychology, 63, 452-5.

3-Cattan M. \& White M., (2005): Preventing social isolation and loneliness among older people: A systematic review of health promotion activities. Aging Society; 25.

4-Dykstra P.\& Fokkema T.,(2007):Social and emotional loneliness among divorced and married men and women: Comparing the deficit and cognitive perspectives. Basic and Applied Social Psychology. 29, 1-12.

5-El-Dosoky, M., M., (1996). Arabic translation of psychological loneliness scale, El- Monofia university, faculty of specific education.

6-Flood M., (2005): Mapping Loneliness in Australia. The Australia Institute, Discussion. Paper No. 76.

7-Gitter S., \& Baumeister R., (2009): The role of hostile cognition in shaping aggressive responses to social exclusion. Journal of Personality and Social Psychology: 96, 45-59.

8-Haukka J., Suominen K., Partonen T. et. al., (2008): Determinants and outcomes of serious attempted suicide: A nationwide study in Finland, 1996-2003. Am J Epidemio. 167(10):1155-63.

9-Heinrich, L., \& Gullone, E., (2006). The clinical significance of loneliness: A literature review. Clinical Psychology Review: 26, 695-718.

10-Junginger J. \& McGuire L., (2004): Psychotic motivation and the paradox of current research on serious mental illness and rates of violence. Schizophrenia Bulletin: 30 (1), 21-30.

11-Lincoln, T., Lullman, E., \& Rief, W., (2007) : Correlates and long-term consequences of poor insight in patients with schizophrenia. A systematic review. Schizophrenia Bulletin, 33(6), 1324-1342.

12-Louks S., (2004): Loneliness, affect, and selfconcept: Construct validity of the bradly loneliness scale. Journal of personality assessment (44), 142-7.

13-Milton J., Amin S., Singh S., Harrison G., Jones P., Croudace T., Medley I. \& Brewin J., (2008):Aggressive incidents in first-episode psychosis. British Journal of Psychiatry, 178, 433-440.
14-Monahan J., Steadman H., Silver E., Appelbaum S., Robbins C., Mulvey P., Roth H., Grisso T. \& Banks S., (2001): Rethinking Risk Assessment: The MacArthur Study of Mental Disorder and Violence. New York: Oxford University Press.

15-Russell, W., (1996): Loneliness Scale (Version 3):Reliability, validity and factor structure. Journal of Personality Assessment, 66, 20-40.

16-Steinert T., Sippach T., Gebhardt R., (2002): How common is violence in schizophrenia despite neuroleptic treatment? Pharmacopsychiatry 33: 98102.

17-Weiss R., (2002): Loneliness: The experience of emotional and isolation. MIT press: Cambridge, MA.

18-West D., Kellner R., Moore M., (2006): The effects of loneliness: A review Of the literature. Comprehensive Psychiatry 27:351-363 